\title{
Análise do comércio e serviço espontâneo no Residencial Vista Bela em Londrina-PR 1
}

\section{Analysis of trade and spontaneous service at Residencial Vista Bela in Londrina-PR}

\author{
Calderon, Thaisa Nunes Vicentim'; Moreno, Katiuscia² \\ 1 Universidade Pitágoras Unopar/Unidade Catuaí, Rod. Celso Garcia Cid, s/n - \\ Jardim Burle Marx, Londrina - PR, 86047-500, Brasil, thaisa.nv@gmail.com \\ 2 Universidade Pitágoras Unopar/Unidade Catuaí, \\ katiuscia.moreno@gmail.com
}

\begin{abstract}
RESUMO
O presente trabalho insere-se na discussão da qualidade dos espaços habitacionais financiados pelo Programa Minha Casa, Minha Vida (PMCMV). O programa tem viabilizado a produção de grandes áreas habitacionais nas periferias de cidades brasileiras, sem nenhum planejamento em termos de equipamentos urbanos, áreas de lazer e áreas de abastecimento. Esta forma de produção do espaço tem gerado uma série de problemas urbanos, como por exemplo a emergência de estabelecimentos de comércio e de serviços ocupando unidades habitacionais, alterando o projeto inicial do bairro e evidenciando sua falta de qualidade e eficiência. Sendo assim, o objetivo principal deste trabalho é monitorar o desenvolvimento do comércio e serviço espontâneo a partir de um estudo de caso realizado no Residencial Vista Bela, com 2.712 unidades, em Londrina, PR, e a partir dessa análise, compreender as transformações morfológicas ocorridas no local. O trabalho será desenvolvido por meio do monitoramento in loco do uso do solo do bairro, levantamento fotográfico e análise dos dados levantados a luz da literatura pesquisada. Esta pesquisa contribui para elucidar possíveis reavaliações da política habitacional e fomentar discussões a respeito da qualidade urbana e do papel do setor terciário em empreendimentos do PMCMV, a partir do entendimento das áreas de comércio e serviços como um dos componentes necessários ao habitar.
\end{abstract}

Palavras-chave: Comércio e serviços. Habitação de Interesse Social. Programa Minha Casa, Minha Vida.

\begin{abstract}
The present work is part of the discussion about the quality of the housing spaces financed by the Minha Casa, Minha Vida (PMCMV) Program. The program has made possible the production of large housing areas in the peripheries of Brazilian cities, without any planning in terms of urban equipment, leisure areas and supply areas. This form of space production has

1 CALDERON, Thaisa Nunes Vicentim; MORENO, Katiuscia. Análise do comércio e serviço espontâneo no Residencial Vista Bela em Londrina-Pr. In: II SIMPÓSIO NACIONAL DE GESTÃO E ENGENHARIA URBANA: SINGEURB, 2019, São Paulo. Anais... Porto Alegre: ANTAC, 2019.
\end{abstract}


generated a series of urban problems, such as the emergence of commercial and service establishments occupying housing units, altering the initial design of the neighborhood and evidencing its lack of quality and efficiency. Thus, the main objective of this work is to monitor the development of trade and spontaneous service based on a case study carried out at Residencial Vista Bela, with 2,712 units, in Londrina, PR, and from this analysis, to understand the morphological transformations that occurred on site. The work will be developed through the in loco monitoring of the use of the ground of the neighborhood, photographic survey and analysis of the data raised in the light of the researched literature. This research contributes to elucidate possible reassessments of the housing policy and to foment discussions about the urban quality and the role of the tertiary sector in PMCMV projects, from the understanding of the areas of commerce and services as one of the necessary components when inhabiting.

Keywords: Trade and service. Social housing. Minha Casa, Minha Vida Program.

\section{INTRODUÇÃO}

O programa Minha Casa, Minha Vida (PMCMV) foi lançado pelo governo federal em 2009, com a finalidade de criar mecanismos de incentivo à produção e à aquisição de novas unidades habitacionais pelas famílias com renda mensal de até 10 salários mínimos (BRASIL, 2009). Destacou-se dos anteriores ao destinar grande volume de subsídios à habitação popular, tendo atingido a camada da população de 0 a 3 salários mínimos, até então não contemplada pelas iniciativas federais na área habitacional (ROLNIK, 2014). Porém, apresentou várias fragilidades, limitações e consequências que foram apontadas pela literatura recente sobre o tema habitação no Brasil (ARANTES; FIX, 2009; BONDUKI, 2009; FERREIRA, 2012; CARDOSO; ARAGÃO, 2013; AMORE; SHIMBO; RUFINO, 2015).

A Rede de Pesquisa Cidade e Moradia divulgou em 2015 resultados de uma pesquisa realizada em seis estados brasileiros que avaliou empreendimentos do PMCMV nas escalas: regional, municipal, do empreendimento e da unidade habitacional. Foram constatados problemas que evidenciam a negação do efetivo direito à cidade. Trata-se da replicação de um modelo precário de se "produzir cidades" - grandes conjuntos habitacionais monofuncionais, implantados nas franjas urbanas (periferias), desprovidos de infraestrutura, áreas de abastecimento (setor terciário) e equipamentos públicos. Os empreendimentos têm atuado como frentes de expansão urbana, alargando o perímetro urbano de nossas cidades, numa produção totalmente carente de qualidades urbanas (VICENTIM, 2015). A exemplo desse fenômeno, Londrina aprovou em 2009 o Residencial Vista Bela, onde observa-se a prática dos mesmos padrões de urbanização precária constatados no cenário brasileiro.

Sendo assim, o objetivo desde trabalho é levantar e analisar o desenvolvimento do comércio e serviço espontâneo no Residencial Vista Bela, buscando compreender as transformações morfológicas ocorridas. A modificação nas unidades (que passou a agregar área de comércio e/ou serviços) ocorreu em vários empreendimentos de regiões metropolitanas investigadas pela Rede de Pesquisa Cidade e Moradia: Rio do Janeiro (Ipê de Realengo), Fortaleza (Santo Agostinho, JB Girão e Escritores), Natal (Vivendas do Planalto, Residencial Vida Nova) e Belém (Jardim dos Ipês, Campo Grande, Bairro dos Minérios, Vale do Tocantins). Isso demonstra a incapacidade e fragilidade dos projetos desenvolvidos pelo PMCMV em atender as demandas dos usuários e responder a realidade das famílias. Portanto, este estudo preenche uma lacuna no entendimento do setor terciário nos empreendimentos do programa e pretende-se assim, evidenciar a crítica a esta política habitacional que favorece uma produção deficiente, impactando negativamente as cidades onde se inserem.

\section{METODOLOGIA}

Para desenvolvimento da pesquisa, percorreu-se as seguintes etapas metodológicas: pesquisa bibliográfica a respeito PMCMV; levantamento do uso e ocupação do solo do bairro; levantamento fotográfico do bairro; e análise dos dados levantados a luz da literatura abordada. 
Na pesquisa bibliográfica, levantou-se os principais autores que discutem o tema na atualidade e buscou-se compreender como o PMCMV tem atuado nas cidades brasileiras. Esse entendimento contribuiu para compreensão do contexto em que se insere o Residencial Vista Bela - objeto de estudo.

O levantamento de uso e ocupação do solo e levantamento fotográfico, foi feito em visitas realizadas ao bairro em Fevereiro e Março de 2019, onde registrou-se lote a lote os usos praticados nas unidades habitacionais e fotografou-se os comércios relevantes e áreas públicas.

Concluídos pesquisas bibliográficas e levantamentos, passou-se a elaboração do mapa de uso e ocupação do solo, com os dados coletados e análise comparativa com levantamentos já realizados no bairro em 2015.

\section{RESULTADOS}

\subsection{Apresentação do Vista Bela}

O bairro insere-se contíguo à malha urbana, no extremo noroeste da cidade, caracterizado como uma região carente de urbanização a uma distância aproximada de 8,5 km do centro histórico de Londrina, e a $3,5 \mathrm{~km}$ do eixo de comércio mais próximo, Avenida Saul Elkind (Figura 1). Observa-se sua implantação periférica, prática comum aos empreendimentos da faixa 1 do PMCMV em consequência do valor da terra (CARDOSO; ARAGÃO, 2013; AMORE; SHIMBO; RUFINO, 2015). Esse fator também é ressaltado por Rizek et al. (2015, p. 314), que afirma: "a distância em relação aos serviços, comércio e equipamentos públicos, redes de infraestrutura, incluindo vias e equipamentos de transporte público de massa", passa a ser fator determinante de áreas "baratas" para abrigar a população carente de recursos.

Figura 1- Localização do Residencial Vista Bela na cidade de Londrina - PR.



Fonte: VICENTIM (2015)

A análise espacial do empreendimento, revela a destinação de áreas fragmentadas para equipamentos públicos comunitários, impedindo a implantação dos mesmos devido as condições do terreno (irregulares, pequenos e inclinados); áreas de espaços livres de lazer não urbanizados e adjacentes à área de preservação permanente; e a não consideração de diretrizes de projetos já aprovados por lei, como um corredor de comércio e serviço que passaria pela Avenida Giocondo Maturi, mas foi inviabilizado devido a implantação de 
edifícios verticais lindeiros a rua (Figura 2). A identificação da carência de equipamentos dedicados a educação e saúde para atender a população foi constatada na aprovação do projeto, porém o mesmo foi aprovado sem condições de destinar áreas para esse fim. Posteriormente, houve a discussão de se aprovar um outro loteamento contíguo ao bairro para sanar esta carência. Esses processos reforçam a tendência constatada nos empreendimentos em que o poder público muitas vezes fez o papel de agente facilitador para a implementação dos novos conjuntos habitacionais do programa (CARDOSO; LAGO, 2013).

Figura 2 - Parcelamento do Vista Bela, com identificação de praças e áreas públicas.

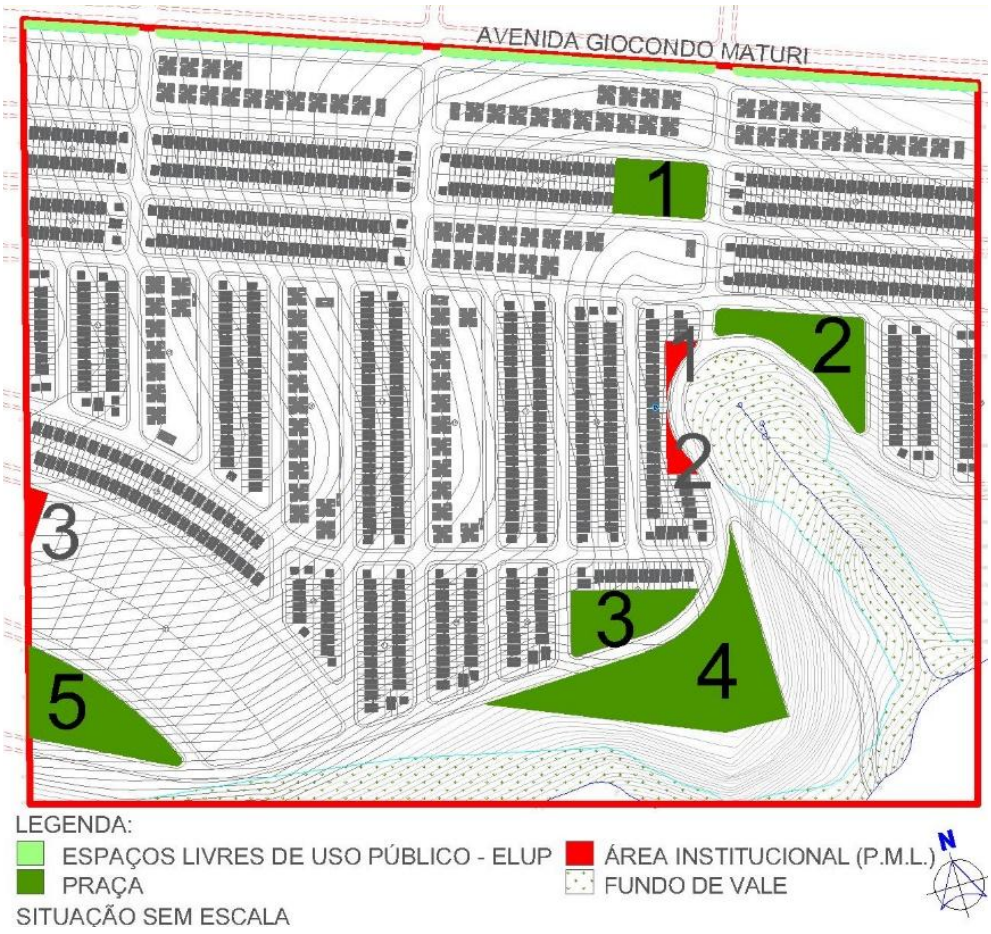

Fonte: VICENTIM (2015)

Figura 3 - Vista do Residencial Vista Bela.



Fonte: Acervo Patrick Rocha

O empreendimento, conta com um total de 2712 unidades habitacionais, sendo essas: 1206 casas do tipo geminadas; 66 casas especiais (para idosos e PNS) e 1440 apartamentos em edifícios multifamiliares; totalizando, assim, uma população de aproximadamente 11.000 
habitantes. O Vista Bela apresenta as características mais significativas da produção do PMCMV Faixa 1: a lógica da escala industrial, na ampla padronização dos projetos e no grande porte dos empreendimentos. De acordo com Rufino (2015), isso ocorre independentemente das diferentes realidades locais.

Figura 4 - Tipologia das unidades habitacionais.

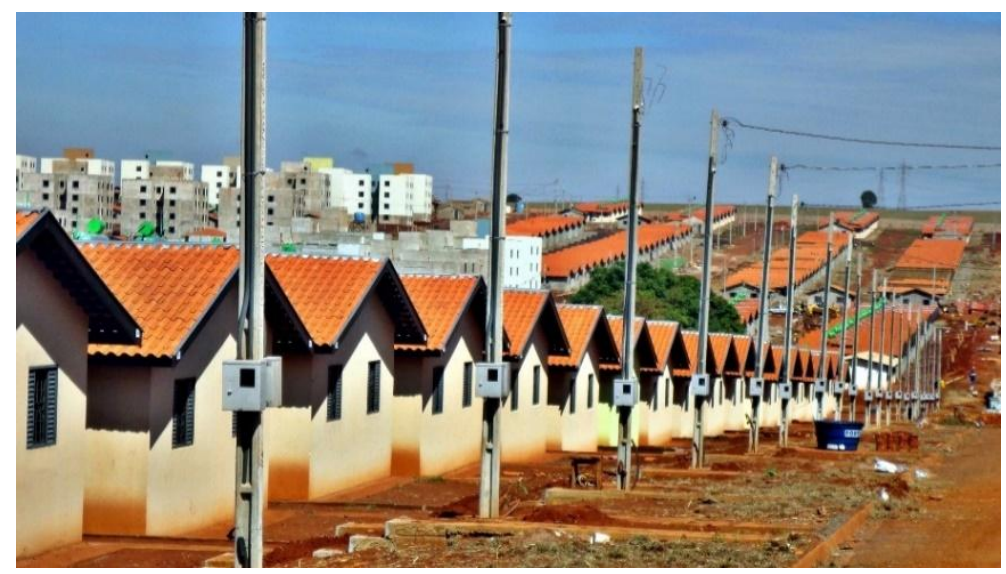

Fonte: Acervo Patrick Rocha

Considerando a localização periférica e a monofuncionalidade do empreendimento, a transformação de parte das unidades habitacionais em estabelecimentos de comércio e serviços seria um processo previsível. Porém a legislação inicial do PMCMV desconsiderava esta necessidade, não permitindo outros usos ou atividades produtivas nas unidades unifamiliares, devido ao fato de que os recursos que custearam os empreendimentos são advindos de fundos de habitação, não podendo ser empregados em outros usos. Portanto, para a Caixa Econômica Federal, segundo Nascimento et al. (2015), a prática é de difícil legitimação.

A implementação do Residencial Vista Bela compactua as características semelhantes aos empreendimentos do PMCMV no Brasil: implantação periférica em virtude do preço da terra, grande escala do empreendimento, padronização das tipologias habitacionais, verticalização da periferia, baixa qualidade arquitetônica e urbanística e flexibilização no processo de aprovação.

\subsection{Análise do comércio e serviços no Residencial Vista Bela}

Segundo Fernandes, Cachinho e Ribeiro (2000), não existe um consenso sobre a definição do termo "comércio", porém, do ponto de vista da sociedade, é comumente entendido como uma atividade na intermediação de bens e serviços no mercado. Considerando o levantamento dos estabelecimentos comerciais no Vista Bela, o processo foi monitorado e mapeado in loco em quatro fases distintas de consolidação do empreendimento:

Tabela 1 - Evolução dos estabelecimentos de comércio e serviços

\begin{tabular}{|c|c|}
\hline Levantamento de campo & $\begin{array}{c}N^{\circ} \text { de estabelecimentos } \\
\text { de comércio/serviços }\end{array}$ \\
\hline Outubro/2012 (1 ano e 4 meses após entrega do primeiro lote de casas) & 26 \\
\hline Dezembro/2013 (2 anos e 6 meses após a entrega do primeiro lote) & 76 \\
\hline Julho/2014 (3 anos após a entrega do primeiro lote) & 82 \\
\hline Abril/2019 (7 anos e 10 meses após a entrega do primeiro lote) & 92 \\
\hline
\end{tabular}

Fonte: VICENTIM (2015), alterado pelas autoras 
Figura 5 - Evolução do comércio e serviço.
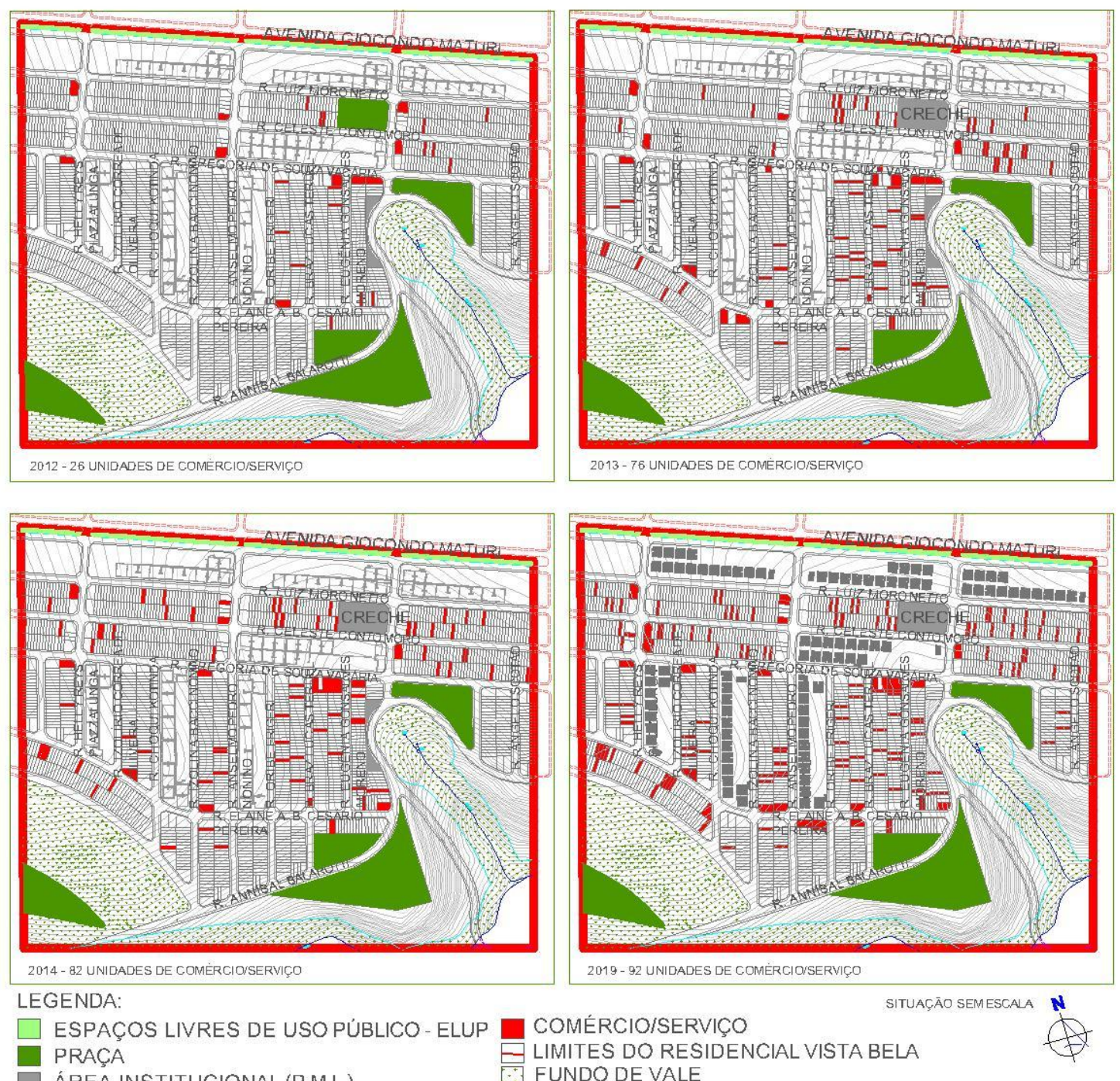

COMÉRCIO/SERVIÇO
LIMITES DO RESIDENCIAL VISTA BELA
FUNDO DE VALE

SITUAÇĀO SEMESCALA N

ÁREA INSTITUCIONAL (P.M.L.)

Fonte: VICENTIM (2015), acrescido do levantamento de 2019 pelas autoras

Entre o primeiro e o segundo mapa, observa-se que o número de estabelecimentos comerciais triplicou. Já nos levantamentos de 2014 e 2019 verifica-se a manutenção de estabelecimentos que se instalaram no início do bairro e a crescente no número de comércios.

Segundo entrevistas realizadas com os proprietários de comércios em 2014, tratam-se de estabelecimentos de comércio familiar na sua maioria de caráter irregular sendo que os proprietários exercem simultaneamente a função de gerência, administração e operação. A maioria já atuava previamente na área e transferiu a atividade para o novo bairro, e o lucro obtido na maioria dos casos, serve para subsistência das famílias (VICENTIM, 2015). Lima et al. (2015, p. 382), ao analisar empreendimentos do PMCMV no Pará, afirmam que o surgimento desse comércio espontâneo ocorre "evidenciando um esforço dos próprios moradores em suprir minimamente a demanda existente, fato também associado a uma estratégia de sobrevivência criada diante das dificuldades de acesso a postos de trabalho nos novos bairros".

A Tabela 2 apresenta as categorias de estabelecimento de acordo com o ramo de produtos comercializados. Verificou-se que aproximadamente um terço do total caracteriza-se como "bar", com $29,41 \%$, indicando o consumo de bebida alcoólica como um lazer frequente. Em segundo, encontra-se o comércio voltado a produtos alimentícios (21,57\%). Vargas e Mendes 
(1999), ao analisarem o comércio não planejado, apontam o ramo de alimentos como uma atividade de fácil ingresso, em virtude do baixo capital inicial, com o foco em produtos de consumo diário. Em seguida, tem-se a categoria de serviços de alimentação: lanchonete, pizzaria, pastelaria, etc., com um percentual de $13,73 \%$ do total de estabelecimentos. A despeito de esse serviço não ser considerado um consumo de primeira necessidade, o número de unidades demonstra a existência de demanda no Vista Bela. Entre os estabelecimentos de serviço, a categoria mais expressiva é a de estética e beleza, com 9,8\% do total.

Quando comparado aos dados levantados em 2019, percebe-se a manutenção dos mesmos estabelecimentos em destaque (bares, mercearias, sacolão, açougue...), porém verifica-se um aumento na quantidade de estabelecimentos de alimentação voltados ao lazer (lanchonete, pizzaria, sorveteria) e voltados a serviços de estética (salão de beleza e barbearia). Tanto a manutenção como o aumento desses índices, reforçam a importância do setor terciário nos empreendimentos dos programas habitacionais, pois além da função de suprimento das necessidades básicas, esse setor cumpre um importante papel de geração de renda para as famílias ali residentes.

Tabela 2 - Classificação dos estabelecimentos.

\begin{tabular}{|c|c|c|c|}
\hline & Classificação & $2014(\%)$ & $2019(\%)$ \\
\hline Serv./Com. & Bar/bar e mercearia & 29,41 & 22,09 \\
\hline Comércio & Mercado/mercearia/sacolão/açougue/doces & 21,57 & 13,95 \\
\hline Serviço & Lanchonete/espetaria/pizzaria/sorveteria/pastelaria & 13,73 & 16,28 \\
\hline Serviço & Salão de beleza/cabeleireiro/Barbearia & 9,8 & 17,44 \\
\hline Comércio & Bazar & 7,84 & - \\
\hline Comércio & Vestuário (novo e usado) & 5,88 & 3,49 \\
\hline Serv./Com. & Pet shop/pet shop e mercearia & 3,92 & - \\
\hline Serviço & Moto táxi & 1,96 & 1,16 \\
\hline Serviço & Vidraçaria & 1,96 & - \\
\hline Serviço & Borracharia/Funilaria/Mecânica & 1,96 & 9,30 \\
\hline Serv./Com. & Cyber / Conserto Eletrônicos / Eletrônicos & - & 4,65 \\
\hline Comércio & Tabacaria & - & 3,49 \\
\hline Serviço & Reciclagem & - & 2,33 \\
\hline Serviço & Lava Rápido & - & 2,33 \\
\hline Serviço & Tatuagem & - & 1,16 \\
\hline Comércio & Revenda de gás & - & 1,16 \\
\hline Serviço & Serralheria & - & 1,16 \\
\hline Comércio & Material de construção & 1,96 & - \\
\hline TOTAL & & 100 & 100 \\
\hline
\end{tabular}

Fonte: VICENTIM (2015), alterado pelas autoras 
Figura 6 - Exemplos de comércios e serviços (2014).
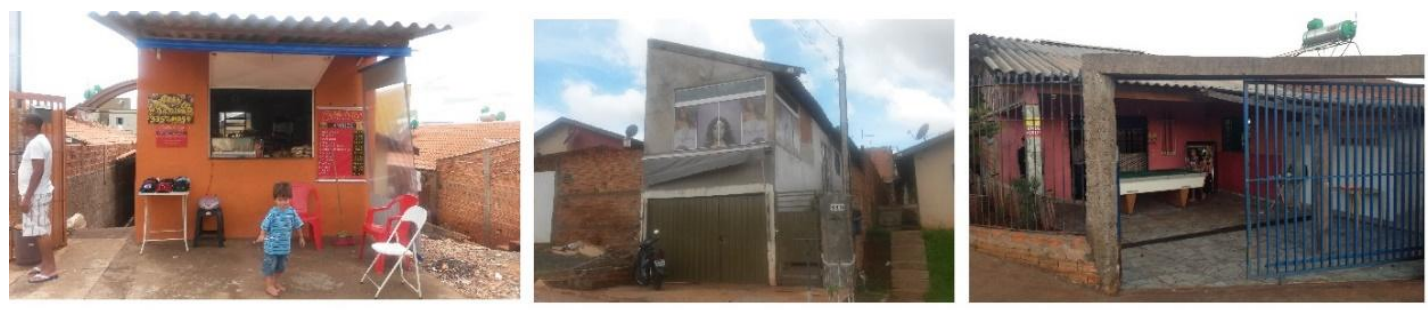

Fonte: VICENTIM (2015)

\section{CONCLUSÃO}

A análise do setor terciário no Residencial Vista Bela o define como um comércio local não planejado, disperso no bairro, composto de estabelecimentos direcionados ao atendimento das necessidades básicas, de uso cotidiano e facilmente acessível. Soma-se a esse fato a predominância de comércios relacionados à alimentação, pois como aponta Rotem-Mindali (2012) o varejo de origem espontânea tende a adequar-se à demanda dos consumidores.

A manutenção e aumento no número de residências que agregaram atividades do setor terciário, nesses oito anos de consolidação do bairro, mostram a importância desse elemento (setor terciário) e necessidade de considerá-lo no planejamento dos empreendimentos. Verificou-se também a dispersão dos estabelecimentos, pois cada empreendedor instalou seu comércio na casa que recebeu da Cohab. Se considerados no projeto do bairro e na locação dos moradores, a Cohab poderia concentrar as pessoas que já exercem atividade do setor terciário numa mesma região, de fácil acesso a todos, criando uma centralidade e propondo locais que poderiam ser adaptados a essa finalidade, assim os moradores que tem o comércio como atividade produtiva, não perderia parte da unidade habitacional.

Verifica-se o papel socioespacial do setor terciário como atividade de desenvolvimento econômico, pois atua como fonte de renda para algumas famílias e tem função de subsistência e como atividade social nos encontros gerados em bares e lanchonetes. De acordo com Vargas (2000), "precisamos considerar estas atividades urbanas em seus dois intrínsecos significados, como uma força social e como força econômica".

Portanto este trabalho buscou trazer a luz a importância do comércio local nos empreendimentos do PMCMV e o fato de considerá-los no planejamento dos bairros resultaria em locais que atendam a demanda real dos usuários e propondo qualidade urbana aos moradores.

\section{AGRADECIMENTOS}

Agradecemos a Fundação Nacional do Desenvolvimento do Ensino Superior Particular (Funadesp), pelo incentivo e financiamento.

\section{REFERÊNCIAS}

AMORE, C. S.; SHIMBO, L. Z.; RUFINO, M. B. C. (Orgs.). Minha Casa... e a Cidade?: avaliação do programa Minha Casa Minha vida em seis estados brasileiros. Rio de Janeiro: Letra Capital, 2015.

ARANTES, P.; FIX, M. Minha Casa, Minha Vida, o Pacote Habitacional de Lula. 2009. Disponível em: <http://www.correiocidadania.com.br/index.php?o

ption=com_content\&task=view\&id=3580\&ltemid =79>. Acesso em: 5 maio 2015.

BONDUKI, N. G. Do Projeto Moradia ao Programa Minha Casa Minha Vida. TD. Teoria e Debate, v. 82, p. 1, 2009. 
BRASIL. Lei $n^{\circ}$ 11.977, de 7 de julho de 2009. Disponível em:

<http://www.planalto.gov.br/ccivil_03/_ato20072010/2009/lei/11 1977.htm>. Acesso em: 10 maio 2014.

CARDOSO, A. L.; ARAGÃO, T. A. Do Fim do BNH ao Programa Minha Casa Minha Vida: 25 anos da política habitacional no Brasil. In: CARDOSO, A. L. (Org.). O Programa Minha Casa, Minha Vida e Seus Efeitos Territoriais. Rio de Janeiro: Letra Capital, 2013.

CARDOSO, A. L.; LAGO, L. C. O Programa Minha Casa Minha Vida e Seus Efeitos Territoriais. In: CARDOSO, A. L. (Orgs.). O Programa Minha Casa, Minha Vida e seus efeitos territoriais. Rio de Janeiro: Letra Capital, 2013.

FERNANDES, J. A. R.; CACHINHO, H. A.; RIBEIRO, C. V. (Coords.). Comércio Tradicional em Contexto Urbano: dinâmicas de modernização e políticas públicas. Lisboa: GEDES-UP, 2000. (Estudo elaborado pelo Gabinete de Estudo para o Desenvolvimento e Ordenamento do Território, da FLUP).

FERREIRA, J. S. W. (Coord.). Produzir Casas ou Construir Cidades? Desafios para um novo Brasil urbano. Parâmetros de qualidade para a implementação de projetos habitacionais e urbanos. São Paulo: LABHAB, FUPAM, 2012.

INSTITUTO BRASILEIRO DE GEOGRAFIA E ESTATÍSTICA. Censo Demográfico 2010. Disponível em: <http://www.censo2010.ibge.gov.br>. Acesso em: 4 out. 2013.

LIMA, J. J. et al. Estratégias de Produção Habitacional de Interesse Social Através do PMCMC na Região Metropolitana de Belém e no Sudeste do Pará. In: AMORE, C. S.; SHIMBO, L. Z.; RUFINO, M. B. C. (Orgs.). MINHA casa... e a cidade? : avaliação do programa Minha Casa Minha vida em seis estados brasileiros. Rio de Janeiro: Letra Capital, 2015.

NASCIMENTO, D. M. et al. Programa Minha Casa Minha Vida: desafios e avanços na Região Metropolitana de Belo Horizonte. In: AMORE, C. S.; SHIMBO, L. Z.; RUFINO, M. B. C. (Orgs.). Minha Casa... e a Cidade?: avaliação do programa Minha Casa Minha vida em seis estados brasileiros. Rio de Janeiro: Letra Capital, 2015

RIZEK, C. S. et al. Viver na Cidade, Fazer Cidade, Esperar Cidade. Inserções Urbanas e o PMCMV Entidades: incursões etnográficas. In: AMORE, C. S.; SHIMBO, L. Z.; RUFINO, M. B. C. (Orgs.). Minha Casa... e a Cidade?: avaliação do programa Minha Casa Minha vida em seis estados brasileiros. Rio de Janeiro: Letra Capital, 2015.

ROLNIK, R. (Coord.). Ferramentas Para Avaliação da Inserção Urbana dos Empreendimentos do PMCMV. Equipe Laboratório Espaço Público e Direito à Cidade (LabCidade). Faculdade de Arquitetura e Urbanismo - Universidade de São Paulo, nov. 2014.

ROTEM-MINDALI, O. Retail Fragmentation vs. Urban Livability: applying ecological methods in urban geography research. Applied Geography, v. 35, p. 292-299, Nov. 2012.

RUFINO, M. B. C. Um Olhar Sobre a Produção do PMCMV a Partir de Eixos Analíticos. In: AMORE, C. S.; SHIMBO, L. Z.; RUFINO, M. B. C. (Orgs.). Minha Casa... e a Cidade?: avaliação do programa Minha Casa Minha vida em seis estados brasileiros. Rio de Janeiro: Letra Capital, 2015.

VARGAS, H. C.; MENDES, C. F. O comércio não planejado e arquitetura comercial de transição. In: INTERNATIONAL CONFERENCE IN RETAILING AND SERVICES SCIENCE, 6., Porto Rico, 1999. Anais... Porto Rico: EIRASS, 1999.

VARGAS, H. C. O Comércio e os Serviços Varejistas: principais agentes e sua inserção urbana. GEOUSP Espaço e Tempo, v. 8, p. 7787, dez. 2000. 
VICENTIM, Thaisa Nunes, Análise do comércio e serviço nos empreendimentos do Programa Minha Casa, Minha Vida (PMCMV): estudo de caso do Residencial Vista Bela - Londrina - PR. Dissertação de mestrado (Mestrado Associado em Metodologia de Projeto de Arquitetura) Universidade Estadual de Londrina - UEL, 2015. 